\title{
Regeneration of Mycelial Protoplasts of Fusarium culmorum
}

\author{
By I. GARCÍA ACHA, F. LÓPEZ-BELMONTE \\ AND J. R. VILLANUEVA \\ Instituto de Biología Celular, CSIC, Madrid-6, Spain
}

(Received 23 May 1966)

\begin{abstract}
SUMMARY
The process of regeneration of Fusarium culmorum protoplasts, obtained by means of strepzyme RA, has been followed. Protoplast regeneration started with the formation of cellular aggregates originating a mass of globular forms which later gave rise to the formation of a pseudomycelial form. Regeneration of protoplasts was formed in three different ways: (a) by means of a chain of yeast-like forms and later originating a germ tube; $(b)$ by direct formation of the germ tube from the protoplast; $(c)$ through a complicated process with the formation of various globular forms and giving rise to the formation of the germ tube at the end. Maximum regeneration, about $80 \%$ of the protoplasts, was found in the presence of $2 \%(\mathrm{w} / \mathrm{v})$ sucrose (or $1 \%(\mathrm{w} / \mathrm{v})$ glucose $+1 \%(\mathrm{w} / \mathrm{v})$ fructose $)+10 \%(\mathrm{w} / \mathrm{v})$ sorbose $+\mathbf{0} \cdot \mathbf{2} \%$ agar + the mineral salts of the Czapek medium. No other sugars were able to substitute for sucrose and sorbose. Agar was the best substance for regeneration; gelatin produced an inhibition. Regeneration was greater under acid conditions, alkaline $\mathrm{pH}$ values interfering with the phenomenon. The number of nuclei/protoplast varied from 1 to 4 , the lack of them in some spherical forms perhaps being the cause of failure to regenerate. No differences were found in the regenerative process as between protoplasts obtained by the use of snail or by microbial lytic enzymes.
\end{abstract}

\section{INTRODUCTION}

Studies of regeneration have been made with the cytoplasmic particles and protoplasts obtained from bacterial and yeast protoplasts obtained by different mechanical and enzymic methods. Regeneration of mould protoplasts was mentioned in the work of Emerson \& Emerson (1958) and of Bachman \& Bonner (1959) with Neurospora crassa protoplasts obtained by the action of a hemicellulase or by using a snail enzyme (Helix pomatia). Strunk (1965) reported regeneration in protoplasts of Polystictus versicolor and Villanueva (1966) in other fungi.

In the present work an attempt was made to examine some of the factors which affect the regeneration process in Fusarium culmorum; the naked protoplasts were characterized by their osmotic fragility and loss of the rigidity characteristic of the mycelial cells. These protoplast bodies appeared to have the same synthetic abilities as whole cells from which they were derived, including the ability to make a new wall. 


\section{METHOD}

Preparation of protoplasts for regeneration studies. Protoplasts of mycelium of Fusarium culmorum (CECT, no. 2148) were obtained as described by Rodriguez Aguirre et al. (1964), by using a lytic system produced by Streptomyces strain RA.

Protoplasts were freed from mycelial debris by passing the suspension through a 11G2 Jena fritted glass filter, without pressure. Pure preparations of protoplasts were washed 3 times with the phosphate + citrate buffer $(0 \cdot 1 \mathrm{M}, \mathrm{pH} 6 \cdot 5)+0 \cdot 6 \mathrm{M}$ mannitol or $\mathrm{NH}_{4} \mathrm{Cl}$, centrifuged at $4000 \mathrm{~g}$ for $15 \mathrm{~min}$., and the pellet resuspended and plated on media containing various supplements. The determination of reversion was made by phase-contrast microscopy in wet mount preparations and in hanging drops containing isolated protoplasts.

Determination of viability. The numbers of living and dead protoplasts were obtained by the methylene blue vital staining technique in which dead organisms stain blue while living organisms remain colourless. Viable counts were made by plating suitable dilutions in appropriate media.

Nuclear staining and microscopic examination. Protoplast suspensions and intact mycelium were stained with alkaline Nile Blue $\mathbf{A}$ by a modification of the method of Gancevici, Stoian \& Keller (1962). A drop of the protoplast suspension previously washed with the stabilizer solution was placed on a microscope slide, mixed with 1 drop of $0.1 \mathrm{M}$-glycine buffer ( $\mathrm{pH} 10)$ and 1 drop of Nile Blue A solution ( $0.02 \%$, $\mathrm{w} / \mathrm{v}$ ) and then examined under a coverslip with the phase-contrast microscope. This technique clearly showed a light purple nuclear body and a blue-green cytoplasm with orange lipid inclusions.

Attempts were also made to differentiate nuclei by the use of acridine orange solution $(1 / 100,000)$ in the fluorescence microscope. The nuclei were stained bright green and the cytoplasm appeared yellow-green.

\section{RESULTS AND DISCUSSION}

\section{Microscopic observations on protoplasts; number of nuclei}

In Fusarium culmorum, by the use of the strepzyme preparation from Streptomyces RA, the hyphal content between two septa is liberated into one or more protoplasts (Villanueva, 1966). Thus, one protoplast does not always correspond to a single cell (López-Belmonte, García Acha \& Villanueva 1966). Not all the protoplasts formed from the mycelium are similar in size. Their contents varies; the number of nuclei, vacuoles and cytoplasmic particles may be quite different (García Acha, López-Belmonte \& Villaneuva, 1966).

According to our observations the number of nuclei between two septa is not constant in the hypha of Fusarium culmorum. The usual number is between 2 and 4 . Nuclei can pass together with the cytoplasmic contents through the septa as we have seen during the liberation of protoplasts. The number of protoplasts liberated from one hyphal compartment is not constant, so that the number of nuclei/ protoplast differs. Attempts to detect nuclei in protoplasts have sometimes failed. They can often be demonstrated by the specific staining techniques used, but the possibility cannot be excluded that they are not observed although they are present in the body. Most of the protoplasts possess at least one or two nuclei; protoplasts 
with three nuclei have been observed. The size of a protoplast is not related to the number of nuclei in it. The importance of nuclear material has always been emphasized in work on regeneration of plant cells and of protozoa. We have suggested that only protoplasts possessing at least one nucleus are able to regenerate cell wall, giving rise to normal mycelial forms, what is in accordance with the results described by Rost \& Venner (1965).

\section{The process of regeneration; changes in morphology}

The various stages of the regeneration process of Fusarium culmorum protoplasts were observed. For $8 \mathrm{hr}$ there was no change in appearance; then the majority of the protoplasts began to develop a protrusion which increased in volume. Some protoplasts formed a large vacuole. Later, the complete regeneration of the abnormal forms into normal mycelium occurred. The earliest visible alteration in the morphology of the protoplasts was the formation of cellular aggregates. Some protoplasts divided and grew during the first $\mathbf{2 4} \mathrm{hr}$, giving more or less pseudomycelial figures with a wide variety of shapes. Other protoplasts developed a kind of spherical structure, not sensitive to osmotic shock, which was able to form hypha. We have observed at least three different ways to start regeneration of protoplast. (a) The protoplast gives a series of yeast-like forms grouped in a chain (Pl. 1, fig. 1). Some of these forms differentiated, becoming more refringent than their neighbours and finally producing a germ tube capable of more or less normal hypha-like growth. (b) The protoplast itself germinated to give a hyphal tube; but this was very uncommon. Individual protoplasts sometimes produced one or more hyphae as direct outgrowths of the mother cell (Pl. 1, fig. 2). (c) The original protoplast, keeping its spherical shape, produced a protrusion which enlarged, giving another spherical body which remained beside the first. Sometimes one of these bodies gave another body of ameboid form and the contents of the previous one were transferred to the neighbouring cell (Pl. 2, fig. 3). The remains of these shells (cell membranes or cell walls) can be seen in the preparation when the protoplasts grew to a mass of more or less bud-like and spherical forms, some with large refringent vacuoles, and some forming germ tubes to give normal mycelium. Plate 3, figs. 4 and 5 show examples of shell liberation.

It was also observed that the empty shells were sometimes filled again, so that the cytoplasmic material moved from one side to another leaving empty spaces during this transfer. The meaning of this phenomenon is unknown.

Emerson \& Emerson (1958) described reversion of neurospora protoplasts upon transfer to media lacking the enzymes used for the digestion of the cell wall. Complete reversion to typical mycelial growth required from a few hours to several days and the type of mycelium formed seemed to depend upon the osmotic strength of the medium. Similar observations were made by Bachman \& Bonner (1959) who stated that some of the protoplasts of Neurospora crassa obtained with the snail lytic enzyme system, when transferred to a suitable liquid or solid nutrient medium regenerated to give normal mycelial growth. The course of regeneration varied greatly.

Our results with protoplasts of Fusarium culmorum were more or less in agreement with these observations. Mycelium originated from an isolated protoplast, after transfer to fresh nutrient medium was able to sporulate normally. These 
reversion cultures were indistinguishable from the original culture in their growth habit, morphology, chemical composition, sensitivity to strepzyme RA, and productivity of protoplasts. This means that a normal mycelium can originate from a protoplast absolutely devoid of cell wall. There is no doubt that the mycelial protoplasts from Fusarium culmorum are true naked protoplasts since the cell wall remains in the preparation, empty but keeping its shape, once the protoplasts have been released (Pl. 3, fig. 6). Electron microscopic studies of ultrathin sections of naked fusarium protoplasts showed no remnants of cell wall on the surface of the cytoplasmic membrane (to be published). As a consequence it ean be concluded that on regeneration of these protoplasts thick cell walls are formed, suggesting de novo synthesis of the rigid envelope. The presence of some vesicles observed in the inner side of the plasma membrane of the ultrathin protoplast sections suggests that those structures may play an important role as carriers of enzymes of precursors of the wall by a process equivalent to reverse pynocytosis (Villanueva, 1966).

Dr C. Strunk (personal communication) informed us that reversion in protoplasts of Polystictus versicolor, obtained by the help of snail enzyme preparation, occurred under suitable conditions in protoplasts which contained two nuclei. Results similar to those described by us in relation to the way in which reversion is produced were also seen; the direct reversion to a hypha which was the beginning of normal mycelium was relatively rare. Most frequently abnormal bud-like forms arose as for the protoplasts of Fusarium and other fungi.

Prolonged incubation of the first generation of globular forms from Fusarium culmorum invariably resulted in mass reversion to the mycelial state. This occurred through an initial increase in the number of large bodies following their separation and in the formation of enlarged filamentous forms. It should be emphasized, however, that all these reversion studies were made on semisolid medium, which is a more effective means of achieving reversion than on solid or liquid media.

\section{Effect of the physical state of the regeneration media}

It has been stated by various workers that the physical state of the regeneration media is a very important factor affecting the phenomenon. Necas (1965) studied the regeneration of protoplasts of Saccharomyces cerevisiae, obtained by an autolytic process, and reported that protoplasts did not regenerate in liquid medium. On the other hand, nearly $100 \%$ regeneration was achieved in $24 \mathrm{hr}$ by cultivation in the same medium solidified by the addition of gelatin $(15 \%)$. Any other substance used to solidify the medium did not give satisfactory results. Regeneration did not take place on the surface of this solid medium, but only when the protoplasts were immersed inside of it. Our results with Fusarium culmorum protoplasts were quite different to those of Necas. Reversion of $\boldsymbol{F}$. culmorum protoplasts to normal hyphae was readily obtained in semisolid agar $(0 \cdot 2 \%, \mathrm{w} / \mathrm{v})$, but reversion was also observed on incubation of protoplasts in solid $(2 \%, \mathrm{w} / \mathrm{v})$ agar, in gelatin $(0 \cdot 2-20 \%)$ and in liquid media (Table 1). Solid media allowed regeneration of $\boldsymbol{F}$. culmorum protoplasts even on the surface. Under the optimal conditions for regeneration ( $2 \%$ sucrose, $10 \%$ sorbose) not more than $3 \%$ regeneration was obtained using gelatin $(0 \cdot 2-$ $20 \%$ ). Only on the surface of plates solidified with $10 \%$ gelatin and seeded with protoplasts did we get a better rate of regeneration. On the other hand, use of $0 \cdot 2 \%$ agar, instead of gelatin, gave over $80 \%$ regeneration. 
The reversion to mycelial forms of Fusarium culmorum from spherical protoplasts was followed conveniently in liquid medium, using microdroplets of regeneration medium containing sucrose + sorbose. In this medium, the uniformity of external pressure, the elasticity of the newly formed membrane and interferencial tension, all tended to conserve the more or less spherical shape of the protoplast. The development of regenerated masses from single protoplasts during the initial stages were similar to the evolution in semisolid medium. A number of protuberances and growing spheres were also formed. At times there were seen local points of weakness where the growing protoplast pinched off a number of small blebs (Pl. 3, fig. 7) which sometimes gave ameboid forms. During the very first stages of regeneration the regenerated forms were osmotically fragile, but once the ameboid and elongated forms were formed the osmotic sensitivity partially disappeared.

Table 1. Influence of the physical state of the media on regeneration of fusarium protoplasts

The basal medium contained the mineral salts of the Czapek medium in distilled water to which sucrose $(2 \%)$ and sorbose $(10 \%)$ were added

$\begin{array}{lc} & \begin{array}{c}\text { Protoplast } \\ \text { regeneration } \\ \text { after incubation } \\ \text { for } \mathbf{1 7} \text { hr }\end{array} \\ \text { Basal medium plus } & (\%) \\ \text { None } & \mathbf{6 5} \\ \text { Agar }(0 \cdot 2 \%) & \mathbf{8 2} \\ \text { Agar }(\mathbf{2} \%) & \mathbf{5 2} \\ \text { Gelatin }(0 \cdot 2 \%) & 2 \\ \text { Gelatin }(1 \cdot 0 \%) & \mathbf{3}\end{array}$

\section{Effect of modifications in the composition of the growth medium on regeneration}

Since Fusarium culmorum grows very well in Czapek medium, this was used as basal medium for the regeneration of protoplasts from mycelium. The best results were obtained with media containing the salts of the Czapek medium $+10 \%(\mathrm{w} / \mathrm{v})$ sorbose $+\mathbf{2} \%(\mathrm{w} / \mathrm{v})$ sucrose $+\mathbf{0} \cdot \mathbf{2} \%(\mathrm{w} / \mathrm{v})$ agar (Table 2). This medium was used throughout our work, unless otherwise stated. Concentrations of sorbose (Table 3) between 2 and $5 \%$ produced little regeneration, and some lysis of the protoplasts. Concentrations of $10-12.5 \%$ were optimal; higher concentrations gave somewhat lower degrees of regeneration. The sole difference found was the increasing refringency of the protoplast contents as the sorbose concentration was increased. No other sugar tested could replace sorbose, but sorbitol replaced sorbose.

Neither glucose nor fructose could replace the sucrose which was used in admixture with sorbose. Glucose + fructose satisfactorily replaced for sucrose. Increasing the concentrations of sucrose and decreasing those of sorbose gave somewhat lower degrees of regeneration (Table 4).

Since there was a possibility that impurities in the sorbose preparation used might affect protoplast regeneration, samples of sorbose from different sources (Merck, Sigma, Pfanstiehl) were tested; the results were very similar with all.

The influence of the nitrogen source of the regeneration media was examined by 
replacing the $\mathrm{NaNO}_{3}$ of the Czapek medium by different nitrogen compounds $\left(\mathrm{NH}_{4} \mathrm{NO}_{3},\left(\mathrm{NH}_{4}\right)_{2} \mathrm{SO}_{4}\right.$, glutamate, glycine, asparagin, casein, peptone). Casein was the best nitrogen source, but no great difference was observed of the other organic and inorganic $\mathbf{N}$ sources.

Table 2. Effect of various carbon sources on the regeneration of Fusarium culmorum protoplasts

The basal medium was formed by the mineral salts of Czapek medium in distilled water $+\mathbf{0 \cdot 2} \%$ agar. All concentrations are expressed in $\mathbf{w} / \mathrm{v}$.

Protoplast
regeneration
after incubation
for $17 \mathrm{hr}$
$(\%)$
10
12
11
24
14
6
11
28
5
78
13
8
12 (lysis)

Table 3. Effect of sucrose and increasing amounts of sorbose on the regeneration of Fusarium culmorum protoplasts

To the basal medium previously described the various concentrations of sugars were added

\begin{tabular}{|c|c|c|}
\hline \multicolumn{2}{|c|}{ Basal medium plus } & \multirow{2}{*}{$\begin{array}{l}\text { Protoplast } \\
\text { regeneration } \\
\text { after incubation } \\
\text { for } 17 \mathrm{hr} \\
(\%)\end{array}$} \\
\hline \multicolumn{2}{|c|}{$\begin{array}{l}\text { Sucrose + Sorbose } \\
(\%) \quad(\%)\end{array}$} & \\
\hline 2 & 2 & 12 (lysis) \\
\hline 2 & 5 & 25 (some lysis) \\
\hline 2 & 10 & 78 \\
\hline 2 & 12,5 & 82 \\
\hline 2 & 15 & 70 \\
\hline 2 & 17,5 & 74 \\
\hline 2 & 20 & 68 \\
\hline
\end{tabular}

Effect of environmental conditions on the capacity for regeneration

The influence of several environmental and chemical factors on regeneration from protoplasts of Fusarium culmorum was examined. Under the optimal conditions previously described, temperatures between $18^{\circ}$ and $33^{\circ}$ did not significantly affect the number of protoplasts able to regenerate in semisolid or liquid medium. When incubation was at $28^{\circ}$ in liquid media aeration had no noticeable effect; shaken and static cultures showed about the same degree of regeneration. 
Different $\mathrm{pH}$ values of the medium showed marked effects on regeneration. When protoplasts were incubated at $28^{\circ}$ statically the maximum regeneration $(70 \%)$ was at about $\mathrm{pH} 6 \cdot 7$. At $\mathrm{pH} 5,50 \%$ of the protoplasts regenerated; at $\mathrm{pH} 8$ only $12 \%$ of the protoplasts reverted to normal mycelium. At pH 9-10 regeneration did not take place; at $\mathrm{pH} \mathrm{3,25 \%}$ of the protoplasts regenerated. At greater than $\mathrm{pH} \mathbf{8}$, regeneration did not occur under our conditions. The curve relating regeneration and $\mathrm{pH}$ value was linear from $\mathrm{pH} 3$ to $6 \cdot 5$, and decreased sharply above $\mathrm{pH} 7$.

Table 4. Effect of various concentrations of sucrose (or glucose + fructose) and sorbose on the regeneration of Fusarium culmorum protoplasts

To the basal medium previously described the various concentrations of sugars were added

\begin{tabular}{|c|c|}
\hline Basal medium plus & $\begin{array}{c}\text { Protoplast } \\
\text { regeneration } \\
\text { after incubation } \\
\text { for } 17 \mathrm{hr} \\
(\%)\end{array}$ \\
\hline $\begin{array}{cc}\% & \% \\
\text { Sucrose } & (2)+\text { sorbose }(10)\end{array}$ & 75 \\
\hline Sucrose $(4)+$ sorbose $(8)$ & 56 \\
\hline Sucrose $(6)+$ sorbose $(6)$ & 27 \\
\hline Sucrose $(8)+$ sorbose $(4)$ & 15 \\
\hline Sucrose $(10)+$ sorbose $(2)$ & 11 \\
\hline Glucose $(2)+$ sorbose $(10)$ & 13 \\
\hline Fructose $(2)+$ sorbose $(10)$ & 11 \\
\hline $\begin{array}{l}\text { Glucose (1) + fructose (1) } \\
+ \text { sorbose }(10 \%)\end{array}$ & 80 \\
\hline
\end{tabular}

\section{Attempts to prevent protoplast reversion}

Attempts to prevent reversion from protoplast to the mycelial form were made by subculturing the initial globular forms in a variety of media. We were not able to show the presence of permanently stable globular forms, possibly because of some factors which affect the successive generations, with a resulting increase in appearance of filamentous forms. The globular proliferation showed intermediate forms more transparent and with less consistency. When protoplasts were kept for 15-20 days in the presence of the lytic enzyme as during protoplast formation, the spherical bodies did not regenerate but many remained alive, as indicated by the vital staining technique, and were able to regenerate when transferred to new media.

\section{Regeneration in other fusarium species}

Reversion from protoplast to mycelial form was noted with all the Fusarium species which we tested ( $F$.oxysporium, F. avenaceum, F.cubense, F. solani, F. roseum, $F$. poae, $F$. decemcellulare, $F$. orthrosporioides), the intermediate stages of the process in general being very like to that described for $F$. culmorum. However, with $F$. orthoceras very abnormal mycelium was regenerated.

Comparison of the regeneration process with protoplasts obtained by means of snail and other lytic enzyme preparation

In the previous experiments protoplasts were always obtained by cell-wall digestion with strepzyme RA (Rodriguez Aguirre et al. 1964). Some experiments 
were done by digestion of Fusarium culmorum mycelium with the digestive juice of Helix pomatia under the same experimental conditions as used with strepzyme RA. Apart from the morphological similarity of protoplasts obtained with strepzyme RA and snail enzyme, perhaps the most direct evidence of similarity was the analysis of the stabilized protoplasts which did not show any residues of materials corresponding to cell walls.

Regeneration of the protoplasts obtained by means of the snail enzyme preparation follows steps very similar, nearly identical, to those described for protoplasts obtained with strepzyme RA. The only significant difference was the formation of a large number of convoluted forms in the protoplasts obtained by strepzyme RA. Regeneration studies with protoplasts obtained with snail enzyme preparations were often complicated by bacterial contamination. Attempts made to obtain protoplasts of Fusarium culmorum by growing the organism on a medium containing high concentrations of sorbose, according to Hamilton \& Calvet (1964), were unsuccessful.

The results here suggest that regeneration of protoplasts to the mycelial form and cell wall formation de novo in Fusarium culmorum can take place and that a very high proportion retain the ability to regenerate and to form new normal cells. However, the process is a slow one. Whether the low rate of regeneration found in these experiments was due to unsatisfactory cultural conditions or to the lack of nuclei in some of them is not yet known.

\section{REFERENCES}

Bachmann, B. J. \& Bonner, D. M. (1959). Protoplasts from Neurospora crassa. J. Bact. $78,550$.

Emerson, S. \& Emerson, M. R. (1958). Production and reversion of protoplast-like structures in the osmotic strain of Neurospora crassa. Proc. natn. Acad. Sci. U.S.A. 44, 668 .

Gancevici, G., Stoian, I. \& Kelder, Z. (1962). Localisation cytochimique des graisses dans les cultures de tissus. Archs. roum. Path. exp. Microbiol. 21, 191.

García Acha, I., López-Belmonte, F. \& Villanueva, J. R. (1966). Obtention of protoplasts from fungal spores. Antonie van Leeureenhoek 32, 299.

Hamrlton, J. G. \& Calvet, J. (1964). Production of protoplasts in an osmotic mutant of Neurospora crassa without added enzyme. J. Bact. 88, 1084.

López-Belmonte, F., García Acha, I. \& Villanueva, J. R. (1966). Observations on protoplasts of Fusorium culmorum and on their fusion. J. gen. Microbiol. 45, 127.

Necas, O. (1965). Mechanisms of regeneration of yeast protoplasts. II. Formation of the cell wall de novo. Folia biol., Praha 11, 97.

Rodriguez Aguirre, M. J., García Acha, I. \& Villanueva, J. R. (1964). Formation of protoplasts of $\boldsymbol{F}$. culmorum by strepzyme. Antonie van Leeurvenhoek 30, 33.

Rost, K. \& Venner, H. (1965). Wachstum von Hefeprotoplasten und ihre Reversion zu intakten Hefezellen. Archiv Mikrobiol. 51, 130.

STrunk, Ch. (1965). Entstehung und Reversion von Basidiomyceten-Protoplasten. In Symposium über Hefe-Protoplasten, Ed. by R. Müller Berlin: Akademie Verlag.

Villanueva, J. R. (1966). Protoplasts of Fungi. In The Fungi. Ed. by G. C. Ainsworth \& A. S. Sussman. Vol. 2, p. 2. New York: Academic Press. 

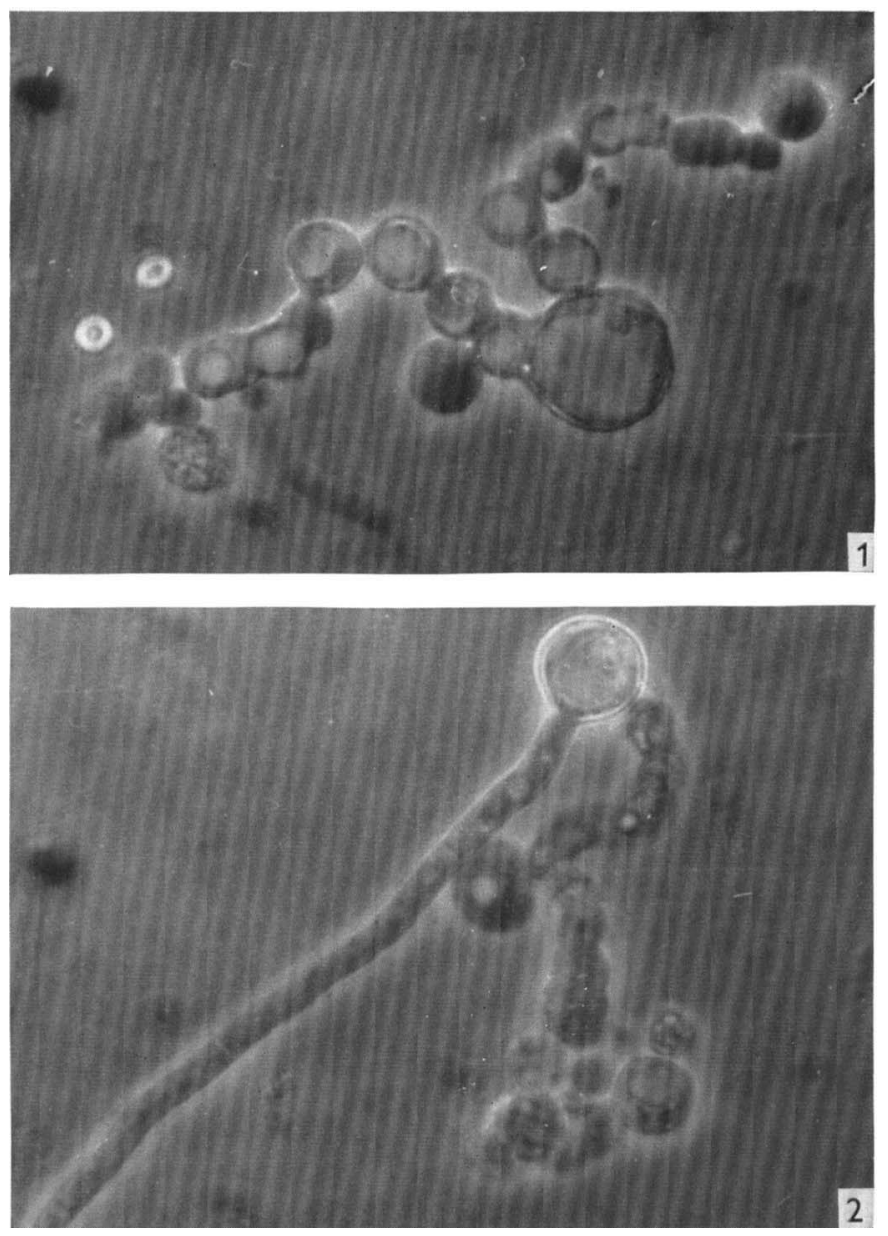

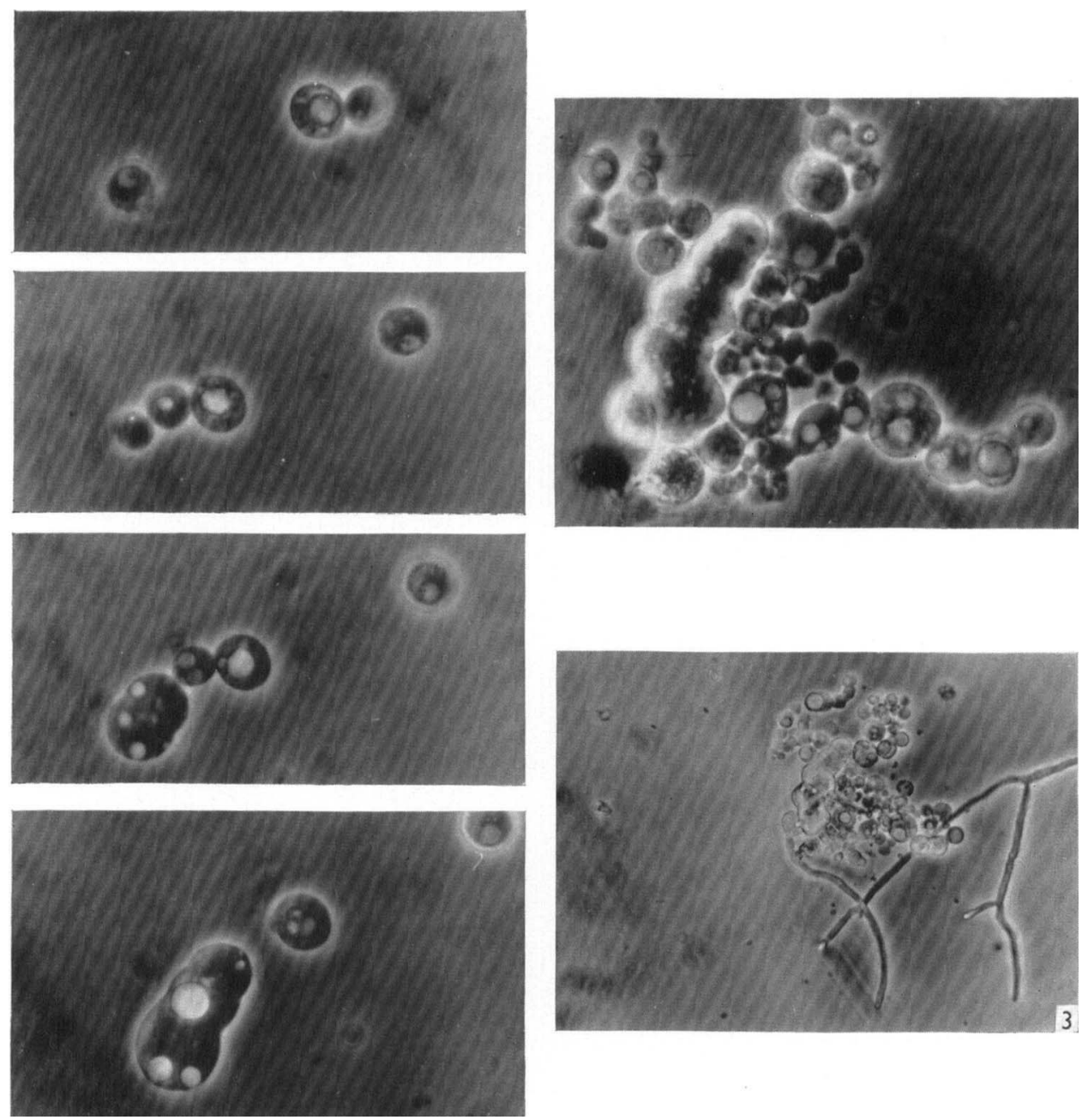

I. GARCÍA ACHA AND OTHERs 

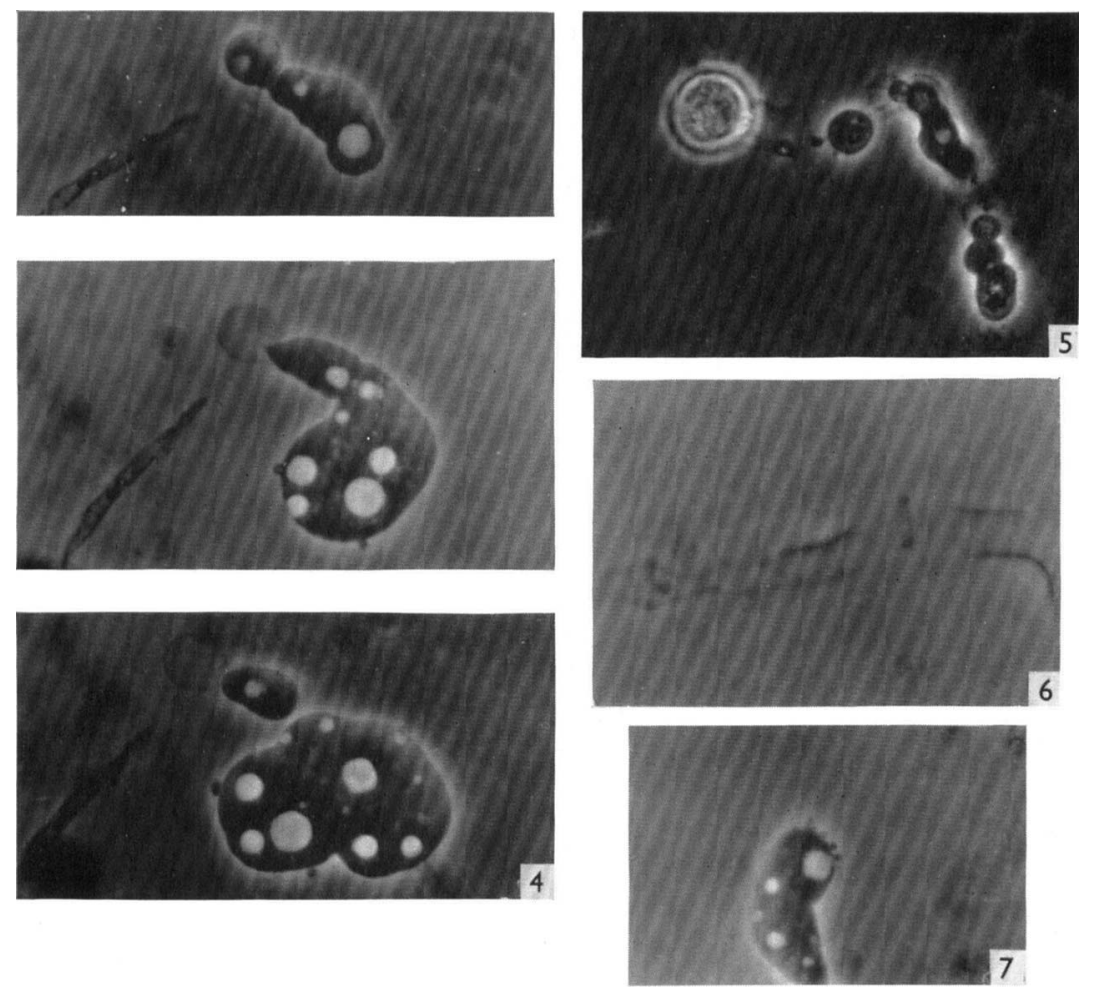

I. GARCIA ACHA AN1 OTHER' 



\section{EXPLANATION OF PLATES}

\section{Plate 1}

Fig. 1. Regeneration of Fusarium culmorum protoplasts. Note the series of yeast-like forms $(\times 6000)$.

Fig. 2. Direct formation of a hypha from a $F$. culmorum protoplast $(\times 6000)$.

\section{Plate 2}

Fig. 3. Another type of regeneration in F. culmorum protoplast. Note the formation of large ameboid forms $(\times 6000)$.

\section{Plate 3}

Fig. 4. Emigration of the protoplast contain showing the remaining empty shells $(\times 6000)$.

Fig. 5. Another example of shell liberation during the regeneration process in $F$. culmorum protoplasts $(\times 6000)$.

Fig. 6. Empty cell walls of $\boldsymbol{F}$. culmorum remaining in the preparation once that the protoplasts were released $(\times 6000)$.

Fig. 7. Ameboid form of a regenerating protoplast of $F$. culmorum showing the formation of small blebs $(\times 6000)$.

\section{Note added in proof}

Trehalose has been used instead of sucrose in combination with sorbose for the process of regeneration of Fusarium culmorum protoplasts but although regeneration occurs it works very slowly: after 4 days incubation normal hyphae are not yet formed, and the chains of regenerated cellular aggregates are very short. 